\title{
Book Review: Marriage Without Borders: Transnational Spouses in Neoliberal Senegal
}

\section{By Dinah Hannaford, University of Pennsylvania Press Reviewed by Aaron M. Ellrich, University of Florida}

This book provides an anthropological perspective of Senegalese migrant experiences and how families abroad and in the homeland cope with distant relations. Each chapter attends to a specific theme which, together, cements an encompassing approach of the challenges Senegalese migrant families grapple with on a day-to-day basis. One of the goals of the book is to offer a more nuanced picture of love in Senegal and its relation to material exchange which the author conceptualizes through the notion of the "flexible family" whose members improvise newly mobile approaches to kin relations as they grapple with impossible expectations of being both "here" and "there". Impossible expectations can be characterized through the six core chapters as followed: (1) adjusting to the dual reality of living in a society that is built on the image of a culture of migration; (2) marrying abroad, with the socio-cultural pressure of the distant (flexible) family being the desired norm; (3) migrant wives in the homeland taking on the role of transnational actors through a politics of gift exchange and reputationbuilding; (4) the use of technologies for surveillance vis-à-vis sexual (in)fidelity; (5) remote intimacy and transnational parenting; and (6) the prospect and challenges of a transnational marriage shifting to reunion

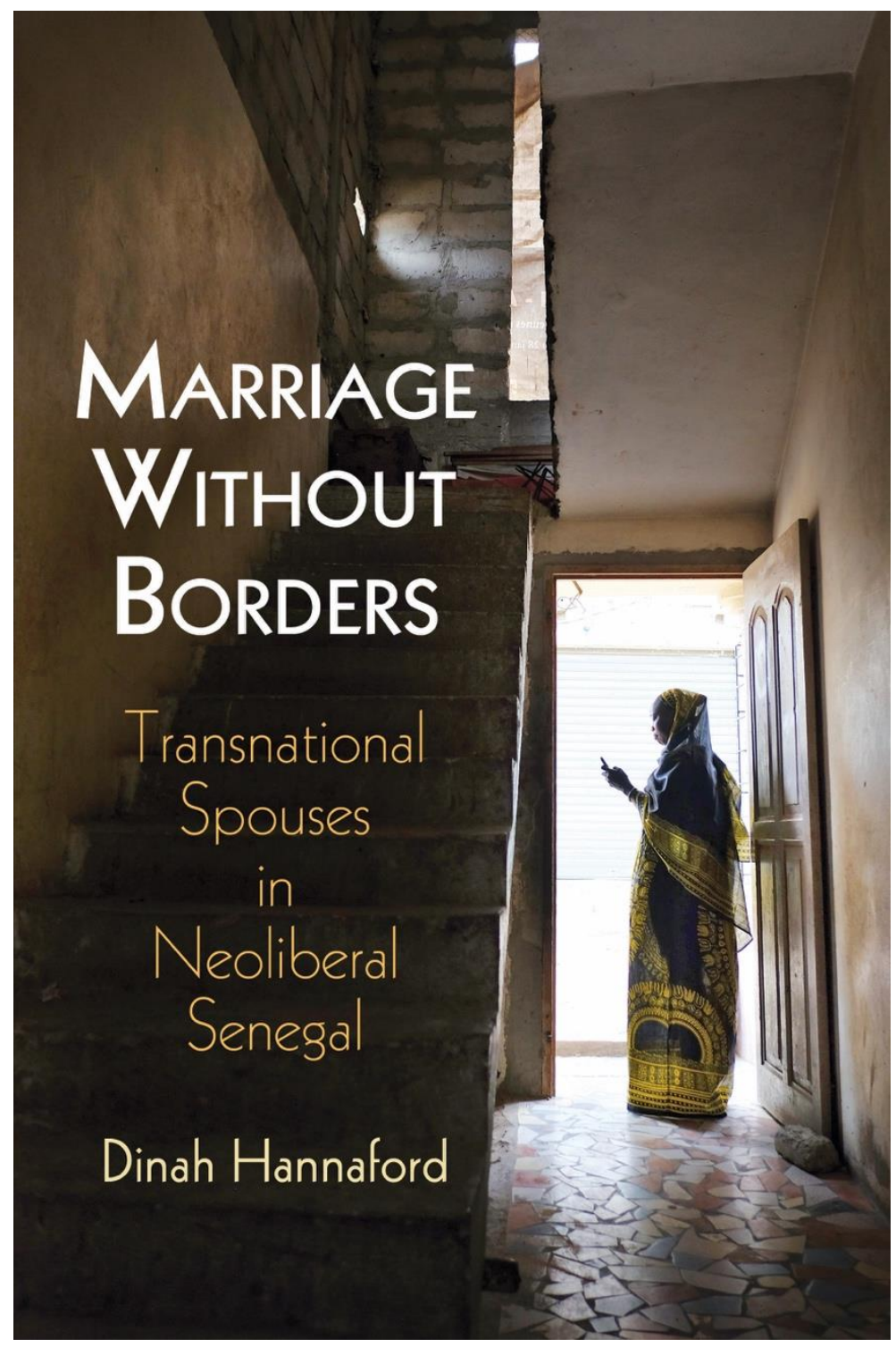
and family-building in the host context.

What bonds each chapter is Hannaford's critique of neoliberal policies in Senegal and their subsequent impact in creating an exodus of Senegalese into the global workforce. Acknowledging that the critique of neoliberalism has been fatigued over the years, what makes Hannaford's approach different is her long-term engagement with Senegalese migrant families (beginning in 2002) and her attention to the ways in which neoliberal forces not only push Senegalese migrant families to adapt to new conditions but also galvanize as well as reorient Senegalese traditional practices. 
For example, the book recognizes how polygamy in many contexts where it is legally sanctioned is on the decline. Nevertheless, in Senegal there are no signs of polygamy in decline and, Hannaford maintains, the practice holds strategic advantages for migrants and may become more common due to the social capital and solidification of a successful Senegalese man having multiple wives. Shifts in customary marriage practices are also recognized in the book as urban women marry migrant men whose families reside in rural regions. What this research shows is how some newlywed women choose to follow the patrilocal tradition of moving into the homes of their husband's family, whose lineages in some cases are of lower caste than the incoming wife's. What is intriguing in this arena of social status difference is how the success of husbands living and working abroad challenges the Senegalese tradition of hypergamy, including the contemporary yearning to reside in the city of Dakar. Furthermore, Hannaford's engagement with newlywed women leaving Dakar to live with their new husband's family in rural areas demonstrates how a reorientation of traditional marriage practices engenders familial tension and frustration among women accustomed to an urban life. This tension and frustration surfaces through in the book's discussion of the Wolof concept seeyi - a period when a new wife moves in with her in-laws to demonstrate she is virtuous, obedient, modest, and pious. The shift from an urban to a rural context for some migrant spouses is intolerable, driving many unable to live the kaw-kaw way of life (i.e., backwards) to leave their husband and return to an urban life.

Cheikh Babou's (2008) study of Wolof hair braiders reveals similar shifts in traditional Senegalese life as hair braiding - conventionally practiced by women of lower social caste - has been transformed into a lucrative business in the U.S. Through a narrative panning between the host country and homeland, Marriage without Boarders builds on Babou's (2008) study of shifts in Senegalese gendered power dynamics. What is different in the book, however, is Hannaford's framing of a Senegalese woman's success not being wholly dependent on physical migration itself but, through strategic selection, its potential realization by marrying a migrant man living and working abroad. At the same time, Hannaford documents how men use migration as a marital strategy as well - many Senegalese men migrate specifically with marriage in mind. It is this dynamic interplay between the sexes that gives the book its strength. For example, readers come to understand that many Senegalese migrant marriages are built on spousal paranoia; specifically, from men living abroad. Chapter 4, "Mobility, Surveillance, and Infidelity," teases out the ways in which paranoia can be assuaged to some degree through surveillance, such as the use of digital technologies and social networks. Through this strategy of techno-social surveillance, Hannaford reveals how these run against the Senegalese image of a successful marriage as migrant wives' power and mobility are reduced when husbands, living abroad, regularly hound them with accusations of infidelity - in one case, a husband's paranoia was so extreme he had a LAN line installed in his wife's home. Generally speaking, much of the book attends to social remittances (Levitt 1998; Vari-Lavoisier 2016). However, rather than focus solely on the positive aspects of global information flows through transnational migration, Hannaford enfolds what could be branded as social externalities as paranoid husbands living in bitim rëw (the world outside of Senegal) send conflicting messages about love, trust, and care back to their wives, causing both spouses extreme anxiety and fatigue.

A testament to Senegal's culture of migration, Marriage without Boarders makes it clear that "marrying a migrant does not necessarily lead to migration" (p. 23). Through her long-term fieldwork, Hannaford reveals how most migrant wives in the homeland are completely unaware of their husband's conditions abroad and, at best, they temporarily reunite every few years. The book builds on Senegalese migrant research in Italy (cf. Riccio and Uberti 2013), bringing much needed attention to the wives and families back home whose husbands live and work in Italy. Moreover, Hannaford 
challenges research that portrays digital communication technologies as devices that bring migrant spouses emotionally closer, arguing that, in the Senegalese case, the ability of men to have constant access to their wives via telephone, Skype, instant message, Western Union, and even the circulation of DVDs in the diaspora, restricts a wife's freedom of movement. The book's contribution to identifying marriage trends in Senegal shows how the "flexible family" has become normalized as unmarried women choose to look past local men - characterized as unfit to support a family - for sturdier husbands living and working abroad. Overall, the books greatest contribution is its capturing of the ways in which neoliberal forces have galvanized and reoriented traditional Senegalese marriage practices; offering scholars working in similar contexts new questions to consider in terms of understanding love, marriage, and family in transnational settings.

\section{References}

Babou, C. A. (2008) Migration and cultural change: Money, 'caste,' gender, and social status among Senegalese female hair braiders in the United States. Africa Today 55(2), 3-22.

Levitt, P. (1998) Social remittances: Migration driven local-level forms of cultural diffusion. International Migration Re view 32(4), 926-948. DOI: $10.2307 / 2547666$

Vari-Lavoisier, I. (2016) The economic side of social remittances: How money and ideas circulate between Paris, Dakar, and New York. Comparative Migration Studies 4(20), 1-34. DOI: 10.1186/s40878-016-0039-6 